\title{
Facilitating Multi-Stakeholder Dialogue and Collaboration in the Energy Transition of Municipalities through Serious Gaming
}

\author{
Tania Ouariachi
}

Citation: Ouariachi, T. Facilitating Multi-Stakeholder Dialogue and Collaboration in the Energy Transition of Municipalities through Serious Gaming. Energies 2021, 14, 3374. https://doi.org/10.3390/ en14123374

Academic Editor: Dario Padovan

Received: 26 April 2021

Accepted: 7 June 2021

Published: 8 June 2021

Publisher's Note: MDPI stays neutral with regard to jurisdictional claims in published maps and institutional affiliations.

Copyright: (C) 2021 by the author. Licensee MDPI, Basel, Switzerland. This article is an open access article distributed under the terms and conditions of the Creative Commons Attribution (CC BY) license (https:/ / creativecommons.org/licenses/by/ $4.0 /)$.
Professorship Communication, Behaviour \& The Sustainable Society, Center of Expertise Energy, Hanze University of Applied Sciences, Zernikeplein 7, 9747 AS Groningen, The Netherlands; t.ouariachi.peralta@pl.haze.nl

\begin{abstract}
Within the EU, energy transition at the local level is embedded in a complex stakeholder network with highly interdependent actors; if these actors have to collaborate to contribute to an efficient transition, they have to initiate a dialogue about their roles and interests. A good way to achieve this goal could be via serious gaming. Scholars suggest that serious games have the potential to increase multi-stakeholder's dialogue and collaboration on climate-change-related issues; however, empirical evidence on the effectiveness, and the process is still limited. The aim of this paper is to use the We-Energy Game as a case study to provide empirical evidence on how serious gaming could facilitate dialogue and collaboration among different stakeholders, and which specific features influence the engagement of participants with the issue. For that purpose, a qualitative analysis on feedback and observations of group discussions is conducted, together with a survey for 125 stakeholders from diverse municipalities in The Netherlands to assess what type of features influence the engagement. The study reveals that the game engages participants mostly at the cognitive level, and that key elements in this process are game design, the debriefing session, and the role of the facilitator.
\end{abstract}

Keywords: energy transition; serious games; stakeholders; local government; cooperation

\section{Introduction}

Our society is facing a number of challenges whose impact is becoming more visible every day, and climate change is considered one of those challenges. Caused by the substantial emission of greenhouse gasses produced predominately by human activity (e.g., combustion of fossil fuels for energy and transportation), climate change is already affecting health, the economy, and the basic needs of citizens [1]. If the problem is largely caused by human behaviour, it also means that it can be solved by humans, at least in relation to the emissions. However, this requires not only individual behavioural change, but also societal behavioural change, modifying deeply rooted systems and structures through the involvement and collaboration of a variety of stakeholders with diverse views and interests. This is seen as a transition process, which according to [2] means "a radical, structural change of a societal (sub)system that is the result of a coevolution of economic, cultural, technological, ecological, and institutional developments at different scale levels". For [3], an efficient energy transition is "a timely transition towards a more inclusive, sustainable, affordable and secure global energy system that provides solutions to global energy-related challenges, while creating value for business and society, without compromising the balance of the energy triangle".

In both definitions above we can observe that energy transition is a complex and urgent process, and that to achieve it efficiently, decisions and actions cannot be addressed by a single institution. The design of energy transition requires a "broad interdisciplinary mobilization of expertise, convictions, resources and multi-stakeholder collaboration" [3]. 
Within this context, local authorities within the European Union (EU) have a key role in energy transition towards a low-carbon, energy-efficient, and sustainable municipality through the development and application of energy policies, but they cannot act alone. On the one hand, they often control a small fraction of local greenhouse gas emissions, and on the other hand, relying on the involvement of local stakeholders-with diverse expertise, convictions, and resources-guarantees innovation and ambitious initiatives in the long term. Local authorities need multi-stakeholder engagement, but how can local governments create awareness of energy transition while enabling dialogue and collaboration among different stakeholders? Only sending information has proven to be insufficient $[4,5]$; therefore, innovative approaches such as "serious gaming" have gained popularity in the last decade. Serious games-games with a purpose beyond entertainment-allow participants to actively engage with actionable information through a game interface [6].

Under these premises, the We-Energy Game was developed. In the game, which can be played online or on a board, a minimum of five players can take the roles of production, planet, profit, people, and balance. From each perspective, players first negotiate which energy source to use and on which area on the map, and then they revise the consequences for the different roles. Through playing the game, participants are expected to become more aware of the complexities and urgency in providing renewable energy, as well as the need to start negotiating with others to in order to develop a sustainable energy mix for their municipalities. Hence, the aim of the We-Energy Game is to improve debate and dialogue and initiate collaboration among different stakeholders in energy transition. The game is expected to create cognitive, emotional, and behavioural engagement with energy transition.

Researchers maintain that serious games could work as effective strategies to raise citizens' engagement with climate-change-related issues [7-9], such as energy transition; however, empirical evidence on the effectiveness and the process to support engagement is still limited [10]. The goal of this paper is, therefore, to introduce the application of the We-Energy Game as a case study to provide empirical evidence on how serious gaming could facilitate dialogue and collaboration among different stakeholders and which specific features influence the engagement of participants with the issue of energy transition.

This paper is organized as follows: first, we introduce a background on the topic. Then, we provide theoretical perspectives that back up this study and the methodology used. Finally, findings, discussion, and conclusions are provided.

\section{Related Literature}

Communicating topics such as energy transition is challenging. According to [11], the first problem is the nature of the topic itself, which is complex for the general public to understand due to the technical, economic, and societal relationships, but also the timerelated constrains. Furthermore, we talk about a long-term process in which the means might change over time. Communicating actions while being flexible remains difficult due to the challenge in envisioning a "specific image" of the future. Finally, in the process, different views and interests on objectives and means are encountered from a variety of stakeholders, creating a "strongly polarized environment". This conflicting environment is also visible in media representation, which even if it is increasing over time, it is often seen as "unbalanced" by both sides of the spectrum, those who criticise it and those who support energy transition [8]. In the case of climate change, the topic is often represented in a "sensationalist and shocking way" in mass media, making people feel distant towards the issue, without power to make changes [12].

Scholars have shown that transmitting information in a unidirectional and passive way or providing mostly statistical data does not contribute to bringing the topic closer to the minds and hearts of people and, therefore, does not create engagement with energy transition. Reference [13] also warn about the "ostrich effect" in which information may be 
avoided entirely if negative expectations exist, for instance, the perception of unaffordability for solar panels or geothermal heat pumps.

All these factors increase the need to search for interactive and innovative approaches to communicate on energy transition and to contribute to stakeholders' engagement in the energy transition process. Serious games-games whose purpose goes beyond pure entertainment to convey ideas, values, knowledge, and skills-have recently emerged as a potential tool for that purpose [6]. The proliferation of visual cultures, the rise in digitalization, and the evolution of interactive media have contributed to this rise in attention among scholars and practitioners, offering new opportunities for engagement with the issue. Sustainability and climate-change-related serious games have been developed "exponentially" in recent years but, especially, in an online format: these types of games differ greatly in game mechanics, technical sophistication, and scientific accuracy. However, many of the scholars agree that role play and simulations are the most dominant genres, and that energy is one of the most recurrent topics [10].

Several researchers have focused on studying how serious games can raise awareness, as well as change attitudes and behaviour towards energy saving and efficiency. Reference [14] found that learners' awareness and behavioural intention was significantly improved after playing a game; Reference [15] found positive outcomes on both attitude and behaviour towards energy efficiency, although significant differences between game and control groups were reduced thereafter. The study by Reference [16] showed how the participation in a social game provoked a reduction in energy use among college students by $2 \%$. However, the savings did not last in the 30 -day follow-up test.

Many studies conclude that serious games that are "properly constructed and validated" have potential as an efficient strategy for engaging with diverse publics [8]. Employing serious games is also seen by researchers and practitioners as a new form of participatory communication that can act as "ice-breakers" to stimulate discussions and initiate co-creating responses. Factors such as the capacity of games to have a direct experience, reflective observation, and exploration of very different ideas can contribute to that goal [17]. As a case study, [18] describe the Maladaptation Game, a game created to help layers taking decisions with regards to the four climate-related challenges in Nordic agriculture: "(a) increased precipitation, (b) increased temperature/risk of drought, (c) increased prevalence of pests and weeds, and (d) a prolonged growing season". In this game, participants individually explore different options and create their own decisions in the game, which are shared in common via the moderator screen. Specific entry points for the dialogue are given through the challenges presented in the game, helping players to elaborate their arguments, question each other, and develop a joint understanding [18].

\section{Theoretical Framework}

\subsection{Engagement}

To test the effects of serious gaming in changing behaviour, one of the most recurrent theories is [19], which states that a "positive attitude towards a concrete behaviour combined with positive subjective norms and a high level of perceived control will likely impact an individual's intention to carry out that behaviour and increase the likelihood that the concrete behaviour will be carried out". In relation to perceived control, and in the field of games, a key concept is self-efficacy, which is "the extent to which people believe that they are capable of doing specific tasks in order to achieve certain goals", according to [20].

Game experience is another area that scholars are currently interested in exploring. The concept of flow - a feeling of high enjoyment and fulfilment—is addressed by [21] in the theory of flow, which suggests eight dimensions: a challenging activity requiring skill; a merging of action and awareness; clear goals; direct, immediate feedback; concentration on the task at hand; a sense of control; a loss of self-consciousness; an altered sense of time. Based on this concept, the EGameFlow [22] was created as a scale to analyse users' enjoyment in e-learning games, including 42 items divided into eight groups: concentration, 
goal clarity, feedback, challenge, control, immersion, social interaction, and knowledge improvement [23].

Less studies are available to test the engagement of players with a particular issue of focus in the game, such as energy transition in our case. While in social sciences, the concept of engagement can have different perspectives, in the field of climate change communication, the conceptualization of engagement by [24] is widely accepted. They define engagement with climate change issues as "individuals' evaluation of and response to climate change which compromises cognitive, emotional and behavioural components". That means that people should understand more (cognitive), but also care about it (emotional) and be stimulated to take actions (behavioural) in order to become engaged.

In this context, the Framework for Climate Change Engagement through Games was developed by [25]. The framework proposes game attributes that can "maximise" the cognitive, emotional, and behavioural engagement of players. The 15 game attributes are categorized in the three dimensions introduced by [24]:

- Cognitive involvement: credible, experiential learning, concrete, challenging, levellingup, fun, achievable, feedback-oriented, meaningful, narrative-driven, simulating.

- Emotional involvement: identity-driven, concrete, challenging, efficacy-enhancing, reward-driven, achievable, feedback-oriented, meaningful, narrative-driven, simulating.

- Behavioural involvement: social, efficacy-enhancing, reward-driven, levelling-up, fun, achievable, feedback-oriented, meaningful, narrative-driven, simulating.

Some of the 15 game attributes fall into all three dimensions. That means these attributes have the potential to engage at cognitive and emotional levels at the same time: achievable, feedback-oriented, meaningful, narrative-driven, and simulating. This paper makes use of this framework to analyse which specific features-and, therefore, dimensions-influence the engagement of participants with the issue of energy transition after playing We-Energy Game.

\subsection{Stakeholders}

In any decision-making process, there are always individuals or groups that have a particular interest or a degree of influence on the achievements of the operations. Reference [26] defines these individuals and groups as "stakeholders". From the point of view of strategic stakeholder management theory, Reference [27] state that the roots of the concept of stakeholders are related to "the diverse nature of what they can demand" from a given organization. The same authors suggest that the more stakeholders an organization has, the more complex stakeholder management will be. They propose the "Power-Interest Grid" with four dimensions [27]: "subjects", who are the stakeholders who have a low degree of power, but a high degree of interest in the organization (they want to influence but cannot modify decisions); "players", who are the stakeholders who have a high degree of power and a high degree of interest in the organization (they are significant partners so one should work with them); "crowd", which is the stakeholders who have a low degree of power and a low degree of interest in the company (they are satisfied with updates); "context setters", who are the stakeholders who have a high degree of power, but a low degree of interest in the organization (they influence the context of the decision). In practice, this model can serve to enhance the proactive management of stakeholders [28].

In the case of energy transition, municipalities (local government) are in a key position to identify actions that best meet the needs in their population. However, an important challenge in the transition is related to the participation of multiple stakeholders, with different points of views and lines of action, including house owners, public authorities, network operators, or producers [29]: due to the lack of "hierarchical and networked relationships" among stakeholders and the existence of different scales and conflicting goals, coordination is complex.

According to [29], there are three main groups of stakeholders at the local level: (a) building-related stakeholders-home owners or housing corporations; (b) stakeholders within current energy systems-grid operators, energy producers and suppliers, installa- 
tion companies, or contractors; (c) governmental and non-governmental organizationsenvironmental NGOS, local energy initiatives, or citizen organizations. The authors add that these groups of stakeholders are all interconnected, and the choices of one group can have an impact on the choices of another.

\section{Materials and Methods}

This study uses both qualitative and quantitative approaches: on the one hand, we conduct a qualitative analysis, focusing on feedback and observations of group discussions held by stakeholders to explore how serious gaming can facilitate dialogue and collaboration; on the other hand, we implement a post-test design research by way of a questionnaire to assess which features influence the engagement of participants with the issue of energy transition and the extent to which participants can engage with the topic at the cognitive, emotional, and behavioural levels through playing the We-Energy Game; this is the most common method in testing the effects of a game [23]. The analysis of qualitative and quantitative data together will, therefore, help in assessing the user experience and participants' feedback.

\subsection{We-Energy Game as a Case Study}

The We-Energy Game is a board game created as a result of research conducted by Frank Pierie, a researcher at Hanze University of Applied Sciences, Groningen. The WeEnergy Game was developed as part of his doctoral research to provide energy stakeholders with practical insights into the possibilities in energy transition. It can be played online or offline by a minimum of five participants. In our case, players played offline. The following table summarizes some characteristics of the game (Table 1):

Table 1. We-Energy Game characteristics.

\begin{tabular}{|c|c|}
\hline Elements & Characteristics \\
\hline Roles & $\begin{array}{l}\text { Production: a project leader who needs to produce a certain amount of energy. } \\
\text { People: the citizens of the area where the game is played. } \\
\text { Planet: how green/clean is the energy production. } \\
\text { Profit: how much profit is made by the different projects. } \\
\text { Balance: how easy to work with is the energy source for the network operator. }\end{array}$ \\
\hline The board & $\begin{array}{l}\text { It makes use of different locations in The Netherlands, using real data based on } \\
\text { own research and an open street map. }\end{array}$ \\
\hline Levels & $\begin{array}{l}\text { The game uses four levels of difficulty by making use of four different maps } \\
\text { (Figure } 1) \text {, allowing players to experience the challenges of making different } \\
\text { towns with different populations sizes energy neutral: Diever (goal: } 25 \text { points), } \\
\text { Meppel ( } 50 \text { points), Assen ( } 75 \text { points), Emmen ( } 100 \text { points). }\end{array}$ \\
\hline $\begin{array}{l}\text { Energy } \\
\text { sources }\end{array}$ & $\begin{array}{l}\text { Energy sources addressed in the game, which are represented on cards, include } \\
\text { large solar parks, solar panels on roofs, large wind turbines, and biogas } \\
\text { production using co-digestion of either energy maize, municipal waste, or } \\
\text { agricultural waste. Additionally, there is the option for energy storage. Each } \\
\text { energy card contains scores, and each role has a different score. The scores are } \\
\text { also based on realistic effects of each variable and refer to the amount of energy, } \\
\text { emissions, and impact. }\end{array}$ \\
\hline Mission & $\begin{array}{l}\text { The mission in the game is to make a town or city electrically energy neutral. } \\
\text { From their respective roles, participants have to discuss and negotiate which } \\
\text { energy source they want to employ and on which location on the map. Once } \\
\text { agreement is reached, they place the icon that represents that energy source on } \\
\text { the map and they check the consequences for each of the roles. Most energy } \\
\text { sources have some positive and negative scores for the roles (Figure 2). The } \\
\text { game finishes when all roles reach the total score for the selected town, } \\
\text { maintaining a positive balance (e.g., } 50 \text { points in the case of Meppel). }\end{array}$ \\
\hline
\end{tabular}




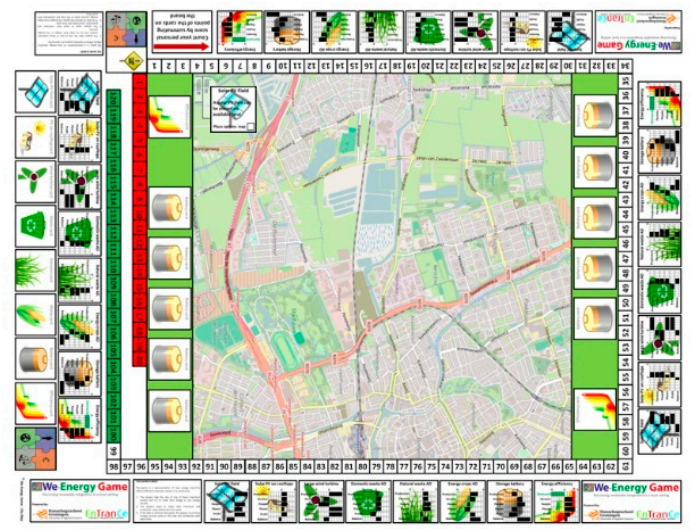

Figure 1. Map of the game.

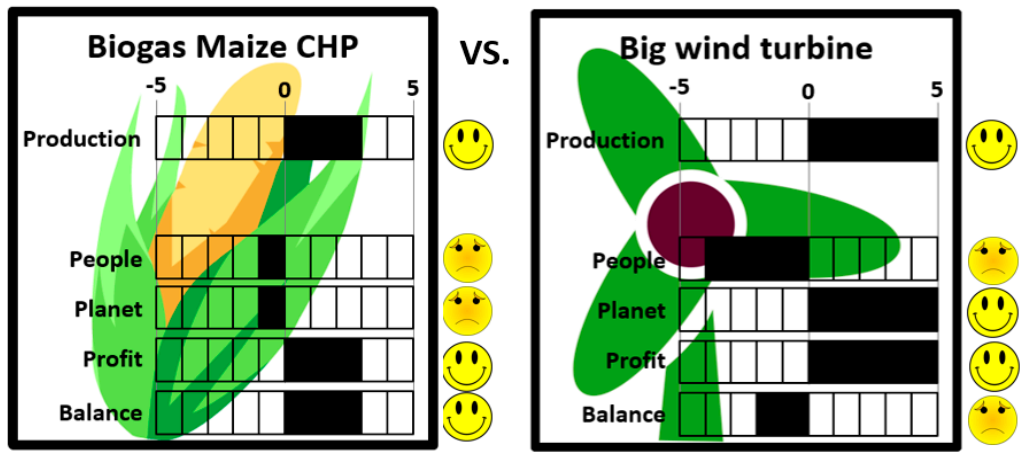

Figure 2. Scores for each role, depending on energy source.

\subsection{Sample and Game Sessions}

A total of 125 stakeholders involved in the energy transition of municipalities in The Netherlands participated in this study, with ages that range from 22 to 70 years old (male: 84; female: 41). Their profiles are very diverse and include energy producers and suppliers, real-estate agents, entrepreneurs, municipality workers (managerial and assistant positions), members from educational institutions (professors and students), members from citizen and environmental groups, journalists, and home owners. Profiles of stakeholders can be categorized in the three different groups defined by [29]: buildingrelated stakeholders, stakeholders within current energy systems, and stakeholders from both governmental and non-governmental organizations.

Data for this study were collected from 6 different sessions, each of them in a different municipality (these municipalities belong to the Northern region of The Netherlands and all have a similar population size-between 8000 and 10,000); therefore, they also share similar challenges in energy transition; these municipalities were not preselected, but instead, the game sessions were requested by municipalities, which means that local government officials themselves were in charge of inviting a diverse range of stakeholders to be part of the game and providing the location. Each single session counted with the participation of approximately 15-50 stakeholders, and it took approximately $2 \mathrm{~h}$ to $3 \mathrm{~h}$ on average, including welcoming words by organizers, explanation about the goals and instructions of the game by the We-Energy Game facilitator, gameplay (usually two rounds, corresponding with two different maps and, therefore, levels), and debriefing time.

Participants were randomly assigned to different tables to play the game-each table would contain a minimum of five players; however, during the debriefing time, groups were dissolved to make the discussion collectively. They were also informed about the purpose of the research and gave their informed consent to the study and publication of results, guaranteeing their anonymity and privacy. 


\subsection{Qualitative Analysis}

Group discussions can be seen as "arenas" for sense-making and co-construction of meaning by encouraging people to expose their individual understandings and contextualize their experiences in interaction with the rest of participants. [30]. The rich data derived from group discussions can allow researchers to analyse content as well as process. While most studies have focused on "what" participants express in groups by using content analysis (e.g., topics and conflict points), we concentrate on the "how": how participants interact with the game dialogue and collaboration. Process-oriented studies in the field of climate change communication have addressed the use of metaphors, analogies, distinctions, and story-telling (e.g., [31,32]).

During a We-Energy Game session, group discussions take place in two different stages: first, during the gameplay, when negotiating which energy source should be employed in the map and why; secondly, discussions are also held after playing the game in a debriefing session, which is facilitated by a moderator (We-Energy Game expert).

In this study, we analyse feedback and observations made by participants during discussions while playing and after playing, focusing on two different categories in relation to engagement: (a) interactivity: relating to criteria such as game dynamics and mechanics; (b) relevance: covering criteria such as purpose, information, as well as the framing. Similar criteria are presented in game evaluation studies [33].

\subsection{Quantitative Analysis}

During our study, we distributed a questionnaire to test the opinion of players regarding the We-Energy Game, taking into account the 15 game attributes derived from the Framework for Climate Change Engagement through Games [25]:

- Achievable: promoting actions within the reach of the individual.

- Challenging: a task that requires effort to perform.

- Concrete: simple messages, avoiding long texts.

- Credible: trustworthy information.

- Efficacy-enhancing: promoting a feeling of empowerment.

- Experiential learning: doing rather than thinking.

- Feedback-oriented: evaluation of current performance relative to a goal.

- Fun: amusement that hooks.

- Identity-driven: connections to relevant personal experiences.

- Levelling-up: long-term goal-directed behaviour facilitated by clear milestones.

- Meaningful: evoking intense feelings.

- Narrative-driven: stories or accounts of events.

- Reward-driven: return for a performance of a desired task.

- Simulating: modelling reality by creating imaginary worlds.

- Social: activating networking.

Respondents are asked to rate those game attributes on a ten-point Likert scale ranging from "strongly disagree" to "strongly agree". Questionnaires are distributed just after playing the game, while informing them about the aim of the study and the anonymity and privacy of their responses. For that purpose, their names in the questionnaires are translated into a number. The questionnaires were pretested with a group of 5 experts and 5 participants for clarity and accuracy of questions [25]. Items resemble this study and are adjusted to the game. The data from questionnaires were transferred to the software SPSS Statistics in order to obtain average scores and translate these into points in order to make a ranking.

\section{Results}

\subsection{Interactivity and Relevance}

To test the effects of serious gaming in changing behaviour, one of the most recurrent theories during a We-Energy Game session, decision making takes place collaboratively during the gameplay. In each round, participants have to decide which energy card they 
want to play to move together on the board towards the final score, being aware that each energy card has a different score for the different roles, sometimes positive and other times negative. For instance, for the role "balance" the score for "Biogas Maize CHP" is positive, whereas the "Big wind turbine" scores negative. Within this context, at the beginning of the game, participants are more focused on mechanics and understanding how to move forward to win, but after a while, participants start negotiating from their respective roles, exposing pros and cons, realising that only a mix of resources will help them to achieve the same purpose. In the process, the We-Energy Game facilitator walked from table to table addressing any possible questions.

Therefore, the different energy options available to play in the game and the need to advance towards a common goal to win lead to intensive dialogue about things that they might not even have considered otherwise. One of the most frequent discussions evolved around the complexities in the provision of renewable energy. Stakeholders acknowledge that energy transition is not just a technical issue, but also a social issue.

Through playing the game, stakeholders do not only realize the complexities of energy transition and the availability of different solutions to achieve an optimal balance, but also the need to consider the point of view from all roles involved in the game in the context of the game. After playing, this is translated into the need to start dialogue and collaborations with each other to create a sustainable energy mix for their town or city.

The game design, through different dynamics and mechanics, fosters a shared sensemaking process and stakeholders' engagement with the issue in particular. The two main game dynamics are challenge and collaboration. While challenge is translated into decision making and time pressure mechanics, collaboration is seen in turns and cooperative mechanics.

Participants consider different options while playing, prioritizing considerations and planning resources in a strategic way, by critically analysing and evaluating information received. In the game, after 30 min of playing, participants are given a countdown of $10 \mathrm{~min}$ to finalize the game. The We-Energy Game is a good example of how serious games can employ cooperation mechanics, which is an element missing in the majority of these types of serious games. Since the first round of the game is played in turns without taking the scores of the other role into consideration, players see a glimpse of the reality of energy transition. While some roles score points quite easily, some will only earn negative points, and there is nothing they can do about it, except play a beneficial card during their own turn. Having to move your pawn backwards every turn gives the players a sense of urgency and makes them more aware of the consequences of these actions. After the first round, the concept of rounds and turns is gone, since the players now work together to try to solve the problem in front of them.

In addition, it is important to add that while some of the participants were not used to playing games, the simple mode of interaction, the structure, and the card-playing format enabled most of them to engage smoothly. Generally, players mentioned that the WeEnergy Game was not difficult to play, among other reasons, because of the employment of visuals and short texts on the cards. A factor that could have helped in this was playing one short round (20 points per role) as an example to make participants understand how to proceed. Another factor is having a map in the background of the board. It is easy and does show the impact on the environment that most people can relate with.

There are some elements that could hinder the flow of the gameplay. First, just few players were eager to finish the game so they went faster through some of the rounds without evaluating and reflecting among all the options. Secondly, sometimes participants started to discuss around the scores in the game and if they were evidence-based, losing the focus. In this case, the facilitator played an important role in guiding the sessions and observing points of interest and debate to bring them to the group discussions at the end.

After the game, there is time for debriefing and debating. Group discussions can be designed according to different formats, depending on the purpose at hand: from structured interview sessions, where the facilitator keeps more control of the interaction, to open-ended conversations, where the facilitator takes a secondary role of [8]. In the case 
of the We-Energy Game, the facilitator takes this second approach, introducing thematic areas for discussion among participants and explaining complex and abstract issues. One of those thematic areas introduced by the facilitator to trigger the dialogue is what their role is in the energy transition of their municipalities. In this context, participants set clear targets for each stakeholder and plan how to collaborate to achieve those targets. The council representative usually takes notes of the co-created local strategies and reflects with stakeholders on how to integrate them into the regional energy strategy.

Every session can be different, and some are livelier than others. Some of the factors influencing the group dynamics are related to the mood of participants that specific day. Some of the stakeholders take the chance to persuade others to understand their own situation and feel more comfortable raising their concerns first and more aggressively. However, in some occasions, these types of participants are put at a table with stakeholders with different communication styles and interests, which can also cause great discussions and an important learning process for everyone involved. This also creates a networking process among stakeholders.

In some sessions, some participants started with a pessimistic feeling (overwhelmed by complexities of energy transitions, cynicism about reaching collective agreements), which along the way slowly turned into more positive feelings, perhaps when they became more used to the game dynamics. Another factor that contributed to the optimism and, therefore, facilitated dialogue and collaboration was focusing the discussion on those easy and visible measures with a short-term impact first, leaving the bigger steps for later. In fact, research in the field of psychology has shown that people are more likely to achieve goals when they are small and attainable. In words of [34], this is called "shrink the change": break down the change until it no longer spooks the elephant.

Lastly, in response to a question posed by the facilitator, participants reflected on the relevance of the game in different collaborative settings, highlighting the potential of using the game to stimulate dialogue on energy transition among practitioners and policy makers. Therefore, stakeholders saw the game as an "eye opener" and arena to support joint understanding of the challenges at hand by providing entry points from different perspectives (Figure 3).

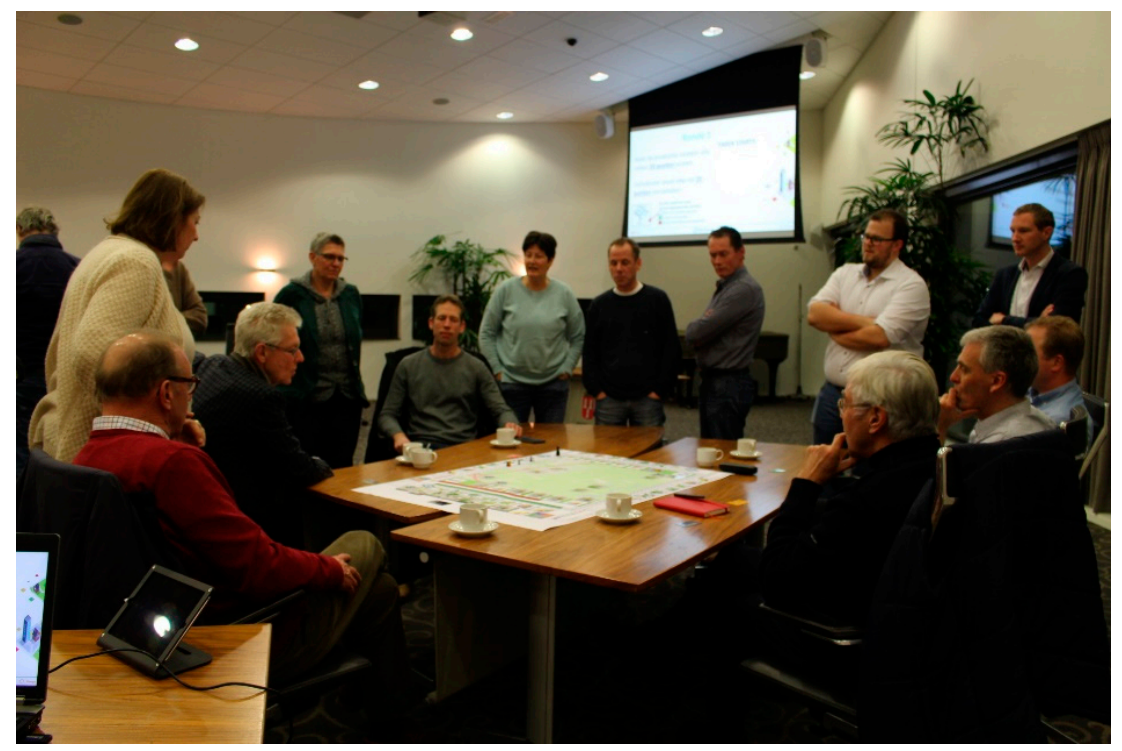

Figure 3. Game session held in one of the municipalities.

\subsection{Factors Influencing Engagement}

First of all, we are interested in analysing the score of each game attribute in order to develop a ranking of attributes based on the Framework for Climate Change Engagement through Games [25]—see section Engagement. For that purpose, we first calculated the 
average obtained in each of the 15 attributed (based on the 120 responses) and, then, translated these averages into points (because we use a ten-point Likert scale, the maximum score is 100 points). After scores were provided for each of the attributes, a dividing line of three valorisation scenarios was estimated after calculating the normalized punctuation in percentiles, selecting as high-valued those attributes that achieved a score over seventy points, and as low-valued those with less than forty-seven points (percentiles 75 and 25, respectively). Therefore, the following scenarios are established: if the attribute receives less than forty-seven points, it is considered to be low-valued by participants; if it receives between forty-eight and sixty-nine points, it is considered to be medium-valued; if it receives more than seventy points, then the attribute is considered to be high-valued.

As can be observed in the table below (Table 2), out of the 15 game attributes, 11 are considered to be highly valued by participants who took part in this study. In addition, we observe that We-Energy Game receives the highest scores on the social and fun game attributes, and the lowest on reward-driven attributes.

Table 2. Average score and points for each game attribute.

\begin{tabular}{ccc}
\hline Game Attributes & Average & Points \\
\hline Social & 8.2 & 82 \\
Fun & 8.2 & 82 \\
\hline Concrete & 7.8 & 78 \\
Challenging & 7.6 & 76 \\
Experiential learning & 7.5 & 75 \\
Feedback-oriented & 7.5 & 75 \\
Levelling-up & 7.4 & 74 \\
Identity-driven & 7.4 & 74 \\
Achievable & 7.3 & 73 \\
Credible & 7.2 & 72 \\
Simulating & 7.2 & 72 \\
Meaningful & 6.9 & 69 \\
Narrative-driven & 6.8 & 68 \\
Efficacy-enhancing & 6.7 & 67 \\
Reward-driven & 6.5 & 65
\end{tabular}

If we integrate these game attributes into their dimensions, we observe that attributes valued as high are:

- Cognitive (nine out of 11): credible, experiential learning, concrete, challenging, levelling-up, fun, achievable, feedback-oriented, simulating.

- Emotional (six out of 10): identity-driven, concrete, challenging, achievable, feedbackoriented, simulating.

- Behavioural (six out of 10): social, fun, levelling-up, achievable, feedback-oriented, simulating.

In order to have a more general overview and explore the potential of the We-Energy Game to engage participants at the cognitive, emotional, and behavioural levels, we conducted a sum of scores per dimension; to be able to compare and weigh each of them, we also calculated the percentages, taking into account that the total number of attributes per dimension is different according to the original framework (11 in cognitive and 10 in emotional and behavioural).

As can be seen in Table 3, the cognitive dimension receives the highest percentage, followed by behavioural and then emotional. That means that the game has greater potential to making people think more and possibly learn more about energy transition. The following figure summarizes the findings, representing with bigger font size the game attributes with the highest valorisation from participants (Figure 4). 
Table 3. Total score and percentage per engagement dimension.

\begin{tabular}{ccc}
\hline Dimension & Total Score & Total Percentage \\
\hline Cognitive & 814 & $74.0 \%$ \\
Emotional & 717 & $71.7 \%$ \\
Behavioural & 727 & $72.7 \%$ \\
\hline
\end{tabular}

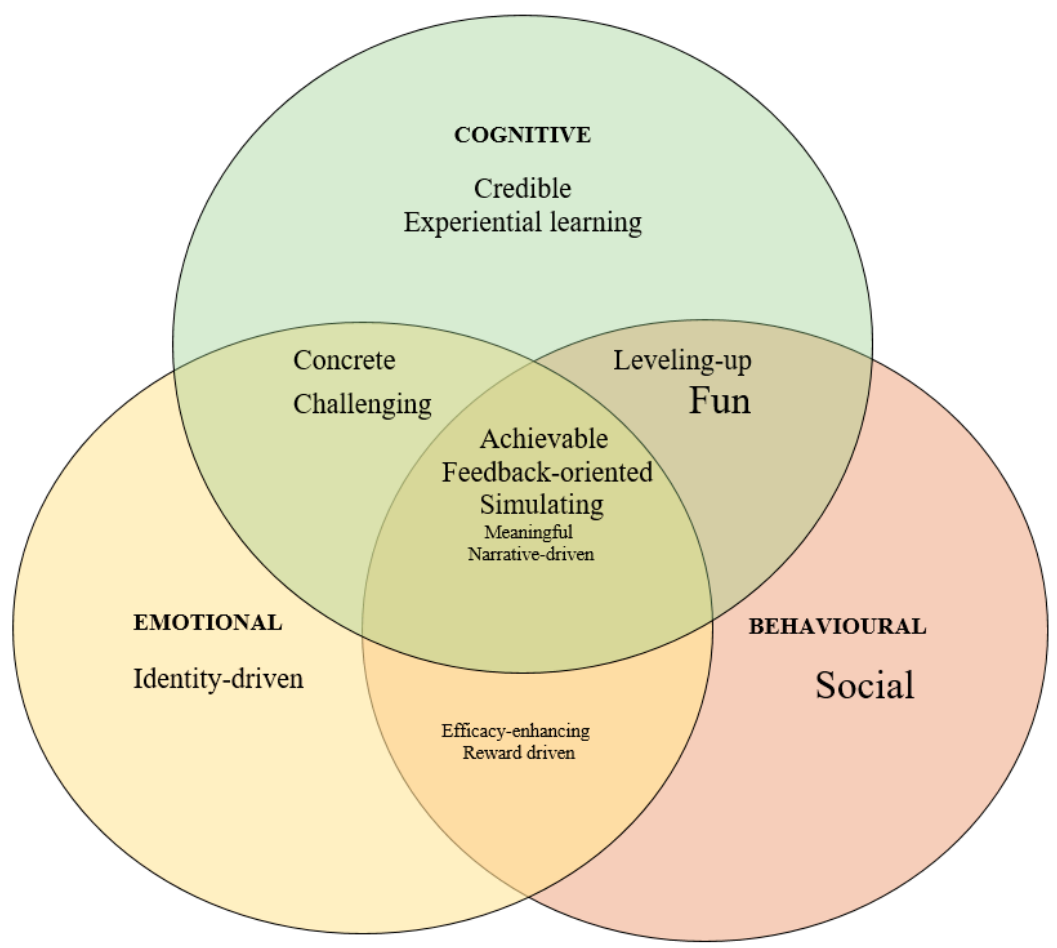

Figure 4. Results summary.

\section{Discussion and Conclusions}

The energy transition process is embedded in a complex stakeholder network with highly interdependent actors. The design of an effective energy transition requires a "broad interdisciplinary mobilization of expertise, convictions, resources and multi-stakeholder collaboration" [3]. If different stakeholders need to collaborate on energy transition, they need to understand each other and initiate a dialogue about their roles, motivations, and actions. The We-Energy Game was designed as a tool to raise awareness about energy transition and bring people together to engage in the exploration of roles and measures from different perspectives, assessing the urgency and complexities involved in the process. In this sense, one can conclude that the game helped municipalities to facilitate the initial dialogue and collaboration needed among stakeholders to start addressing energy transition challenges and possible solutions within their municipalities. Even though the aim of the study was not to analyse the individual cases, similarities, and differences, concluding observations reveal that the game has achieved the same intended purpose among the six different municipalities. Unfortunately, we do not have enough evidence to draw conclusions on the effects of playing the game in the medium or longer term.

The intended purpose was achieved partly by having a stimulating gameplay, which allowed participants to engage in debating and negotiating options that they might not have considered otherwise; this is one of the strengths of serious games as stated by other authors [9]. One of the added values of this study is to show that the game design, through different dynamics and mechanics, fosters this shared sense of making processes and stakeholders' engagement with the issue in particular. Depending on the game design, the flow of the group dialogue might be enhanced, in comparison to a stricter setting, which 
puts a "stronger step-by-step focus on the discussions", as other studies have previously shown [8].

Another added value of this study is to offer a tool to analyse which specific features influence the engagement of participants with the issue and at which level (cognitive, emotional, behavioural). In our case study, we have found out that the game engages participants mostly at the cognitive level, and that the two features that have influenced engagement the most are the social and fun aspects, identified as fundamental by players. It is important to be aware that the degree of engagement may also be affected by participants current position in life (gender, age, education, and income level); socio-economic factors (home-ownership and energy bills), socio-institutional factors (sense of community and trust), and environmental factors (resiliency, environmental concern and desire to reduce $\mathrm{CO}_{2}$ emissions).

A key element in this whole process is the role of the facilitator. Previous studies on focus groups highlight the importance for moderators to be aware of group dynamic aspects impacting the interaction, such as some participants dominating the discussion at the expense of others $[35,36]$. To address this, scholars recommend moderators to explicitly or implicitly steer the debate to ensure that others participate in the discussion [37]. The moderator should make clear from the beginning that there are no right or wrong answers and that the goal is not to make agreements from that moment, but to generate a broad map of opinions and engage in a rich dialogue [8]. As the literature also highlights, another important task for moderators is to facilitate both individual and group reflection during the debriefing as part of the process [38]. The moderator or facilitator should have didactical and technical skills to make the sessions more efficient.

In conclusion, this study offers evidence on how serious gaming could facilitate dialogue and collaboration among different stakeholders and which specific features influence engagement.

One of the main limitations of this study is that our chosen research method relies on the opinions of the player and does not depend on all of the information that can be collected regarding what happened within the game. Another problem relates to the fact that it is almost impossible to completely isolate the game itself and the role of the facilitator during gameplay and after playing, which might have influenced the players' opinions. We are also aware of possible confirmation bias, which has been tackled by continuously evaluating impressions and participants' responses and ensuring that assumptions were kept away. The social desirability bias could have also played a role in the course of the debate, so the moderator made respondents feel that there were no right or wrong answers so that they could comfortably present their own perspectives.

We encourage researchers to further explore how games can facilitate a multi-stakeholder dialogue and collaboration in energy transition by implementing other research methods and by doing a follow-up study to evaluate to what extent those debates really contributed to policy making. This study shows how integrating gaming and focus groups provides a key role to facilitators; therefore, another interesting line of research is related to the role of moderators in the process.

Funding: This research received no external funding.

Institutional Review Board Statement: Not applicable.

Informed Consent Statement: Not applicable.

Acknowledgments: I would like to thank Frank Pierie, Mathieu Przbybyla, Ronnie Huisman, Roel van Veen, and Robin Vredeveld for their support.

Conflicts of Interest: The author declares no conflict of interest. 


\section{References}

1. IPCC. Climate Change 2014: Synthesis Report. Contribution of Working Groups I, II and III to the Fifth Assessment Report of the Intergovernmental Panel on Climate Change; Pachauri, R.K., Meyer, L.A., Eds.; IPCC: Geneva, Switzerlnd, 2014; 151p.

2. Rotmas, J.; Loorbach, D. Complexity and Transition Management. J. Ind. Ecol. 2009, 13, 184-196. [CrossRef]

3. World Economic Forum. Fostering Effective Energy Transition. A Fact-Based Framework to Support. Decision-Making; Insight report; World Economic Forum: Cologny, Switzerland, 2018.

4. Cooper, C.B. Media literacy as a key strategy towards improving public acceptance of climate change science. BioScience 2011, 61, 231-237. [CrossRef]

5. Moser, S.C. Communicating climate change: History, challenges, process and future directions. WIREs Clim. Chang. 2010, 1, 31-53. [CrossRef]

6. Frasca, G. Play the Message: Play, Game and Video Game Rhetoric. Ph.D. Thesis, IT University of Copenhagen, Copenhagen, Denmark, 2007.

7. Reckien, D.; Eisenack, K. Climate change gaming on board and screen: A review. Simul. Gaming 2013, 44, 253-271. [CrossRef]

8. Wibeck, V.; Neset, T.S. Focus groups and serious gaming in climate change communication research. A methodological review. WIREs Clim. Chang. 2020, 11, 664. [CrossRef]

9. Wu, J.S.; Lee, J.J. Climate change games as tools for education and engagement. Nat. Clim. Chang. 2015, 5, 413-418. [CrossRef]

10. Ouariachi, T.; Gutiérrez-Pérez, J.; Olvera-Lobo, M.D. Can serious games help to mitigate climate change? Exploring their influence on Spanish and American teenagers' attitudes. Psyecology 2018, 9, 365-395. [CrossRef]

11. Kreuza, S.; Ploß, E. Why, and what will it look like? Evaluating energy experts' responses concerning the German Energiewende and their implications for communication efforts. Nord. J. Appl. Ethics/Etikk i Praksis 2019, 13, 59-79. [CrossRef]

12. O'Neill, S.; Nicholson-Cole, S. Fear Won't Do It: Promoting Positive Engagement With Climate. Sci. Commun. 2009, 30, 355-379. [CrossRef]

13. Karlsson, N.; Loewenstein, G.; Seppi, D. The ostrich effect: Selective attention to information. J. Risk Uncertain. 2009, 38, 95-115. [CrossRef]

14. Yang, J.C.; Chien, K.H.; Liu, T.C. A digital game-based learning system for energy education: An energy conservation pet. Turk. Online J. Educ. Technol. 2012, 11, 27-37.

15. Gustafsson, A.; Bang, M.; Svahn, M. Power Explorer-A casual game style for encouraging long term behavior change among teenagers. In Proceedings of the International Conference on Advances in Computer Enterntainment Technology; ACM: New York, NY, USA, 2009; pp. 182-189.

16. Reeves, B.; Cummings, J.J.; Scarborough, J.K.; Yeykelis, L. Increasing energy efficiency with entertainment media: An experimental and field test of the influence of a social game on performance of energy behaviors. Environ. Behav. 2015, 47, 102-115. [CrossRef]

17. Kiili, K. Evaluations of an experiential gaming model. Hum. Technol. 2006, 2, 187-201. [CrossRef]

18. Asplund, T.; Neset, T.S.; Käyhkö, J.; Wiréhn, L.; Juhola, S. Benefits and challenges of serious gaming-The case of The Maladaptation Game. Open Agric. 2019, 4, 107-117. [CrossRef]

19. Ajzan, I. The Theory of Planned Behavior. Organ. Behav. Hum. Decis. Process. 1991, 50, 179-211. [CrossRef]

20. Bandura, A. Social Foundations of Thought and Action: A Social Cognitive Theory; Prentice-Hall: Englewood Cliffs, NJ, USA, 1986.

21. Csikszentmihalyi, M. Flow: The Psychology of Optimal Experience; Harper \& Row: New York, NY, USA, 1990.

22. Fu, F.L.; Su, R.C.; Yu, S.G. EGameFlow: A scale to measure learners' enjoyment of e-learning games. Comput. Educ. 2009, 52, 101-112. [CrossRef]

23. Bellotti, F.; Kapralos, B.; Lee, K.; Moreno-Ger, P.; Berta, R. Assessment in and of Serious Games: An Overview. Adv. Hum. Comput. Interact. 2013, 136864, 1-11. [CrossRef]

24. Lorenzoni, I.; Nicholson-Cole, S.; Whitmarsh, L. Barriers Perceived to Engaging with Climate Change among the UK Public and Their Policy Implications. Glob. Environ. Chang. 2007, 17, 445-459. [CrossRef]

25. Ouariachi, T.; Gutiérrez-Pérez, J.; Olvera-Lobo, M.D.; Maibach, E. Framework for climate change engagement through serious games: A proposal of game attributes. Environ. Educ. Res. 2018, 25, 1-16.

26. Freeman, R.E.; Parmar, B.L.; Harrison, J.S.; Wicks, A.C.; Purnell, L.; De Colle, S. Stakeholder Theory: The State of the Art. Acad. Manag. Ann. 2010, 4, 403-445.

27. Ackermann, F.; Eden, C. Strategic Management of Stakeholders: Theory \& Practice. Long Range Plan. 2011, 44, 179-196.

28. Van Wijk, B. Stakeholder Involvement in the Energy Transition-A Grid Company's Perspective. Bachelor Thesis, Faculty: BMS: Behavioural, Management and Social Sciences, Almelo, The Netherlands, 2019.

29. Bekebrede, G.; van Bueren, E.; Wenzler, I. Towards a joint local energy transition process in urban districts. Sustainability 2018, 10, 2602. [CrossRef]

30. Wilkinson, K.K. Between God and Green: How Evangelicals Are Cultivating a Middle Ground on Climate Change; University Press Oxford: Oxford, UK, 2016.

31. Asplund, T. Natural versus anthropogenic climate change: Swedish farmers' joint construction of climate perceptions. Public Underst. Sci. 2016, 25, 560-575. [CrossRef]

32. Wibeck, V. Social representations of climate change in Swedish lay focus groups: Local or distant, gradual or catastrophic? Public Underst. Sci. 2014, 23, 204-219. [CrossRef] [PubMed] 
33. Mitgutsch, K.; Alvarado, N. Purposeful by design? A serious game design assessment framework. In Proceedings of the International Conference on the Foundations of Digital Games; ACM: New York, NY, USA, 2012; pp. 121-128.

34. Health, C.; Health, D. Switch: How to Change Things When Change is Hard; Random House Business Books: New York, NY, USA, 2010; pp. 1-320.

35. Kitzinger, J. The Methodology of Focus Groups: The Importance of Interaction between Research Participants. Sociol. Health Illn. 1994, 16, 103-121. [CrossRef]

36. Morgan, D. Focus Groups and Social Interaction. In The Sage Handbook of Inteview Research: The Complexity of the Craft, 2nd ed.; Gubrium, J., Holstein, J., Marvasti, A., McKinney, K., Eds.; Sage: Thousand Oaks, CA, USA, 2012; pp. 161-176.

37. Grønkjær, M.; Curtis, T.; de Crespigny, C.; Delmar, C. Analysing group interaction in focus group research: Impact on content and the role of the moderator. Qual. Stud. 2011, 2, 16-30. [CrossRef]

38. Crookall, D. Serious games, debriefing and simulation/gaming as a discipline. Simul. Gaming 2010, 41, 898-920. [CrossRef] 